\title{
Effect of Different Combinations of the Growth Factors and Hormones on invitro Maturation of Goat Preantral Follicles
}

\author{
P. Shankaraiah ${ }^{1 *}$, B. Swathi ${ }^{1}$, G. Aruna Kumari ${ }^{2}$, B. Priyanka ${ }^{2}$, \\ Ch. Srinivasa Prasad ${ }^{1}$ and R.U. Amin ${ }^{2}$
}

${ }^{I}$ Department of Physiology, College of Veterinary Science, Rajendranagar, PVNR Telangana

Veterinary University, Hyderabad, Telangana - 500030, India

${ }^{2}$ Department of Veterinary Gynaecology and Obstetrics, College of Veterinary Science, Rajendranagar, PVNR Telangana Veterinary University, Hyderabad,

Telangana - 500030, India

*Corresponding author

A B S T R A C T

\begin{tabular}{|c|c|}
\hline & \multirow{6}{*}{$\begin{array}{l}\text { A series of experiments were carried out with different combinations of various growth } \\
\text { factors and hormones like Growth Hormone }(\mathrm{GH}) \text {, Insulin like Growth Factor-I (IGF-I), } \\
\text { Epidermal Growth Factor (EGF), Thyroxin }\left(\mathrm{T}_{4}\right) \text { and Follicle Stimulating Hormone (FSH) } \\
\text { in culture medium to support growth and development of goat preantral follicles (PFs) } \\
\text { (diameter ranging from } 150-400 \mu \text { ) in vitro for a period of eight days and the retrieved } \\
\text { oocytes from cultured preantral follicles were kept for incubation in in vitro maturation } \\
\text { media (IVM) for } 27 \text { hours. The development of the cultured PFs was assessed by the } \\
\text { proportions of follicles exhibiting growth, increase in follicular diameter, antrum } \\
\text { formation and extrusion of oocytes in vitro. During eight days culture period, the } \\
\text { proportion of PFs exhibiting antrum formation (89.33 } 1.86 \text { ) and extrusion of oocyte } \\
\left(15.55 \pm 2.09 \text { ) were highest when the medium was supplemented with } \mathrm{T}_{4}+\mathrm{FSH}+\mathrm{GH}+\mathrm{EGF}\right. \\
\left(\mathrm{T}_{3}\right) \text { having a significant difference with follicles cultured in other treatments. Oocytes } \\
\text { retrieved from PFs grown in different culture media were kept in IVM media. Oocytes } \\
\text { obtained from } \mathrm{T}_{3} \text { treatment }\left(\mathrm{T}_{4}+\mathrm{FSH}+\mathrm{GH}+\mathrm{EGF} \text { ) had maximum percentage of M-II stage }\right. \\
\text { oocytes ( } 38.6 \%) \text { when compared to the other treatments. From the present study, it can be } \\
\text { concluded that, in vitro development of goat PFs could be significantly improved through } \\
\text { addition of } \mathrm{GH} \text {, EGF, T4 and FSH in best combinations. }\end{array}$} \\
\hline Keywords & \\
\hline & \\
\hline Article Info & \\
\hline & \\
\hline & \\
\hline
\end{tabular}

\section{Introduction}

In mammals, the preantral follicles serve as store-house of majority of oocytes. The ovulatory follicle develops from primordial follicle by a process of folliculogenesis. Through this process, a healthy oocyte is usually selected for maturation. Recent advancements in the area of reproductive biotechnology, particularly the animal biotechnology is reaching to the level where it can be successfully utilized for augmenting the livestock productivity. Few current reproductive technologies used for increasing animal productivity are super ovulation, in vitro embryo production, nuclear transfer, 
stem cell culture, transgenic animal production etc. Since these technologies depend on availability of large number of fertilizable oocytes, due to which need arises to produce large number of meiotically competent oocytes from in vitro culture of preantral follicles. Several in vitro studies suggest that the preantral follicles are able to generate competent oocytes that are able to undergo subsequent embryo development in vitro (Arunakumari et al., 2010; Magalhães et al., 2011b). Moreover, the follicular development is regulated by various endocrine and paracrine factors (Araújo et al., 2011). The ovarian follicular development occurs due to action of various growth factors on the receptors that are expressed in a stage-specific form and act synchronically to promote stimulatory and/or inhibitory effects (Almeida et al., 2011). Among various growth factors and hormones, Growth Hormone (GH), Insulin like Growth Factor-I (IGF-I), Epidermal Growth Factor (EGF), Thyroxin $\left(\mathrm{T}_{4}\right)$ and Follicle Stimulating Hormone (FSH) have been highlighted in the present study.

In several mammalian species different IVM culture systems have been established to study oocyte development, and have applied to assisted reproduction in humans and livestock animals. Mouse is the only species in which in vitro maturation (IVM) and in vitro fertilization (IVF) of oocytes from PFs resulted in the birth of live offspring (Eppig and O'Brien, 1996; Liu et al., 2001). However among farm animals, success has been achieved up to embryo development using oocytes from cultured PFs of adult ovaries in pig (Wu et al., 2001a and b), buffalo (Gupta et al., 2008), sheep (Arunakumari et al., 2010) and goat (Magalhaes et al., 2011a) but none of these studies progressed to develop blastocyst except pig. Addition of $\mathrm{GH}(50 \mathrm{ng} / \mathrm{ml})$ resulted in growth of oocytes form goat preantral follicles that were acceptable for IVM and IVF Magalhaes et al., (2011b). Addition of
VEGF-A $\mathrm{A}_{165}$ to the culture medium improved the development of goat PFs cultured in vitro, allowing the production of mature oocytes (Araujo et al., 2011). The reported success in the meiotic maturation of sheep oocytes from cultured PFs has already been published by Arunakumari et al., (2010) by using various growth factors and hormones. However, the study in goats is still awaited. So the present study was aimed to improve the meiotic maturation rate of oocytes by in vitro culture of goat PFs in different combinations/sequences of GH, IGF-I, EGF, $\mathrm{T}_{4}$ and $\mathrm{FSH}$.

\section{Materials and Methods}

Unless otherwise stated, all culture media, hormones, growth factors, PBS and chemicals were purchased from Sigma (St. Louis, MO, USA) and plastics from Nunclon (Roskilde, Denmark). All media were incubated at $39^{\circ} \mathrm{C}$ under a humidified atmosphere of $5 \% \mathrm{CO}_{2}$ in air for $2 \mathrm{~h}$ prior to use. Phosphate buffered saline (PBS), collection medium for PFs [HEPES buffered tissue culture medium 199 supplemented with $0.5 \%$ bovine serum albumin (BSA), $50 \mu \mathrm{g} / \mathrm{mL}$ gentamicin sulphate, $0.23 \mathrm{mM}$ of sodium pyruvate, $2 \mathrm{mM}$ l-Glutamine and $25 \mathrm{IU} / \mathrm{mL}$ heparin], handling medium (collection medium without heparin), stock solutions of EGF and FSH were all prepared as described by Tamilmani et al., (2005). The preparations of thyroxin, GH and IGF-I solutions were made as per Arunakumari et al., (2007, 2010). Bicarbonate buffered tissue culture medium 199 supplemented with $50 \mu \mathrm{g} / \mathrm{mL}$ gentamicin sulphate was used as control medium.

\section{In vitro maturation media}

Control media (TCM199B) was supplemented with $10 \mu \mathrm{g} / \mathrm{ml} \mathrm{FSH,} 10 \mu \mathrm{g} / \mathrm{ml} \mathrm{LH}, 1 \mu \mathrm{g} / \mathrm{ml}$ Estradiol $17 \beta, 50 \mu \mathrm{g} / \mathrm{ml}$ gentamicin sulphate, $10 \mu \mathrm{g} / \mathrm{ml}$ of Bovine serum albumin (FAF) and 
$10 \%$ fetal bovine serum (IVM-I). The prepared media was stored at $4^{\circ} \mathrm{C}$ for up to 1 week in $5 \mathrm{ml}$ disposable syringe with $0.22 \mu \mathrm{m}$ filter attached. Filtered medium was equilibrated for $1 \mathrm{~h}$ at $39{ }^{\circ} \mathrm{C}$ in $5 \% \mathrm{CO}_{2}$ in air under humidified atmosphere prior to use.

\section{Preparation of propidium iodide solution}

Stock solution of propidium iodide (PI) was prepared by reconstituting $5 \mathrm{mg}$ of lyophilized desiccate of propidium iodide ( $\mathrm{P}$ 81845, Sigma, USA) in $5 \mathrm{ml}$ of filtered PBS to yield concentration of $1 \mathrm{mg} / \mathrm{ml}(1 \mu \mathrm{g} / \mu \mathrm{l}) .10 \mu \mathrm{l}$ of this solution was diluted with $990 \mu \mathrm{l}$ of filtered PBS to yield a final concentration of $10 \mu \mathrm{g} / \mathrm{ml}$ PI solution. This solution was stored in $1 \mathrm{ml}$ of plastic aliquots at $4^{0} \mathrm{C}$ in darkness till used.

Collection of ovaries, isolation, selection and culture of preantral follicles

Collection of ovaries, isolation of PFs, classification and selection of PFs for cultures were performed, as described by Arunakumari et al., (2010) and Amin et al., (2013). Briefly each ovary was cut into two halves along its longitudinal axis. The medulla is scooped out from each half. Then, each half of the ovarian cortex was dissected into thin slices using a 26 gauge needle and sterile surgical blade. Under a stereo zoom microscope (Nikon, Japan), these cortical slices were subjected to micro dissection in collection medium for isolation of the PFs, in the size range of 150-400 $\mu \mathrm{m}$. The diameter of PFs was measured using Scopetek software, China. Care was taken to leave a small amount of stromal tissue attached to the basement membrane of the follicles. PFs having a centrally placed spherical oocyte with an intact basement membrane were chosen for culture. The selected PFs were washed thrice in handling and culture medium and placed individually in $20 \mu \mathrm{L}$ droplet of culture medium in $35 \mathrm{~mm}$ tissue culture dishes. The micro droplets were overlaid with autoclaved pre-equilibrated mineral oil and cultured for 8 days in $5 \% \mathrm{CO}_{2}$ incubator at $39^{\circ} \mathrm{C}$. Half of the culture medium was replaced with fresh culture medium every $48 \mathrm{~h}$.

\section{In vitro maturation of oocytes from in vitro cultured follicles}

The in vitro cultured follicles were carefully opened (if the oocytes were not extruded itself) using two $26 \mathrm{G}$ needles attached to $1 \mathrm{ml}$ syringe barrels, to release the oocyte inside after the end of 8 days culture period. The collected oocytes were washed three times in holding medium followed by three washings in the in vitro maturation medium before being placed individually in $\sim 20 \mu \mathrm{l}$ droplets of IVM medium in $35-\mathrm{mm}$ tissue culture dishes. The droplets were overlaid with autoclaved, pre-equilibrated lightweight mineral oil. These culture dishes were incubated at $39{ }^{\circ} \mathrm{C}$ in $5 \% \mathrm{CO}_{2}$ for $24 \mathrm{~h}$ in a $\mathrm{CO}_{2}$ incubator. This procedure regularly supports meiotic maturation of more than $80 \%$ of oocytes collected from the antral follicles in sheep (Rao et al., 2002).

\section{Staining of in vitro matured oocytes}

At the end of the IVM period of 27 hours, the oocytes were denuded of cumulus cells either by repeated pipetting through a fine-bore glass pipette or by placing COCs (Fig. A) in $200 \mu \mathrm{l}$ of hyaluronidase solution for 1 minute and the cumulus cells were denuded off the oocytes by repeated pipetting through a fine bore glass pipette. The denuded oocytes were washed twice in filtered PBS to remove any hyaluronidase solution adhering to the oocytes. Denuded oocytes were placed separately $200 \mu \mathrm{l}$ PI (Propidium Iodide) stain solution for 15 minutes in darkness in normal atmosphere. After the end of 15 minutes staining period, oocytes were washed twice in 
filtered PBS to remove excess PI stain particles adhering to the oocytes.

Morphological evaluation of cultured preantral follicles and nuclear status of oocytes

Morphological evaluation of PFs was done as described by Amin et al., (2013). However, the stained oocytes were examined through an inverted microscope at magnification of 400x with fluorescent illumination equipped with an excitation filter $510-530 \mathrm{~nm}$, emition filter 590 $\mathrm{nm}$ and dichromatic mirror $570 \mathrm{~nm}$ and the nuclear maturation of oocytes was evaluated by observing the GV (Germinal Vesicle) (Fig. B), GVBD (Germinal Vesicle Breakdown) (Fig. C), M-II (Metaphase-II) (Fig. D), UC (Unclassified) stages of oocyte captured by using a digital camera coupled to microscope.

\section{Statistical analysis}

Two way ANOVA procedure, followed by Duncan's multiple range test in SPSS 17 was performed. Percentage data (proportions) was subjected to arcsine transformation prior to comparisons.

\section{Results and Discussion}

In the present study a total of eleven hundred (1125) preantral follicles were kept for in vitro culture in different treatments $\left(\mathrm{T}_{1}-\mathrm{T}_{5}\right)$, out of these a total number of 931 oocytes were retrieved from preantral follicles of different treatments after 8 days of culture period, while remaining were damaged during culture and retrieval time. Among all treatments, $\mathrm{T}_{3}$ were found to be the best combination as proportions of follicles exhibiting growth is maximum $(98.00 \pm 0.87)$ which is significantly higher than control $\left(\mathrm{T}_{5}\right)(\mathrm{P} \leq 0.05)$, however, it does not vary significantly with other treatments $\left(\mathrm{T}_{1}, \mathrm{~T}_{2}\right.$ and $\left.\mathrm{T}_{4}\right)$. This treatment combination also showed better results with respect to average increase in diameter
(42.66 \pm 2.06$)$, antrum formation $(89.33 \pm 1.86)$ and extrusion of oocytes (15.55 \pm 2.09$)$ than $\mathrm{T}_{1}$, $\mathrm{T}_{2}, \mathrm{~T}_{4}$ and $\mathrm{T}_{5}$ (Table 1). Interestingly, none of the oocytes got extruded from control medium. Oocytes, having at least two layers of cumulus cells and evenly granular cytoplasm, retrieved from different treatments of preantral follicular culture after a period of eight days were kept for in vitro maturation in incubator at $38.5^{\circ} \mathrm{C}, 5 \% \mathrm{CO}_{2}$ in IVM media for 27 hours (Table 2). The oocytes collected by aspiration method from antral follicles of ovaries were kept for in vitro maturation as control-II. In order to evaluate the nuclear status of oocytes, surrounding cumulus cells were denuded off and stained with propidium iodide $(\mathrm{PI})$.

The nuclear status was determined by marking the changes like exhibition of metaphase II stage, Germinal vesicle breakdown (GVBD), shedding of polar body after putting oocytes in IVM media. From the present results (Table 2) it can be confirmed that treatment $\mathrm{T}_{3}$ showed higher rate of nuclear maturation as compared to other treatments $T_{1}, T_{2}, T_{4}, T_{5}$ and $T_{6}$. Oocytes from $\mathrm{T}_{3}$ in the IVM medium did not differ significantly with $\mathrm{T}_{1}, \mathrm{~T}_{2}, \mathrm{~T}_{4}, \mathrm{~T}_{5}$ and $\mathrm{T}_{6}$ with respect to parameters like $\mathrm{GV}$ and GVBD. However, the maturation rate in the control medium was significantly lower $(\mathrm{P} \leq$ 0.05) than other treatment groups (Table 2). The present study was further proceeded to perform the comparative study on meiotically competent oocyte (M-II stage) production, after in vitro maturation in IVM media for oocytes obtained from PFs cultured for a period of eight days in different treatments.

In the present study, there was no significant difference observed for oocytes exhibiting GVBD, GV stage of nuclear status in the treatment $\mathrm{T}_{1}, \mathrm{~T}_{2}, \mathrm{~T} 3, \mathrm{~T}_{4}$ and $\mathrm{T}_{6}$ of IVM media. However, none of the oocyte retrieved from PFs cultured in control $\left(\mathrm{T}_{5}\right)$ were matured to GVBD stage. 
Table.1 Effect of various growth factors and hormones in different combinations on in vitro development of goat preantral follicles

\begin{tabular}{|c|c|c|c|c|c|}
\hline Treatments & $\begin{array}{c}\text { Combinations of } \\
\text { different } \\
\text { hormones } \\
\text { (Replicates/ No. } \\
\text { of follicles) }\end{array}$ & $\begin{array}{c}\text { Proportion of } \\
\text { PFs } \\
\text { exhibiting } \\
\text { growth } \\
\text { (Mean } \pm \text { SE) }\end{array}$ & $\begin{array}{c}\text { Average } \\
\text { increase } \\
\text { in diameter }(\boldsymbol{\mu}) \\
\text { of PFs } \\
(\text { Mean } \pm \mathrm{SE})\end{array}$ & $\begin{array}{l}\text { Proportion of } \\
\text { PFs exhibiting } \\
\text { antrum } \\
\text { formation } \\
\text { (Mean } \pm \text { SE) }\end{array}$ & $\begin{array}{l}\text { Proportion of } \\
\text { PFs ovulated } \\
\text { (Mean } \pm \text { SE) }\end{array}$ \\
\hline $\mathbf{T}_{1}$ & $\begin{array}{l}\mathrm{T}_{4}+\mathrm{FSH} \\
(45 / 225)\end{array}$ & $95.55 \pm 1.25^{b}$ & $29.51 \pm 0.81^{b}$ & $74.22 \pm 1.75^{b}$ & $1.33 \pm 0.75^{\mathrm{a}}$ \\
\hline $\mathbf{T}_{2}$ & $\begin{array}{c}\mathrm{T}_{4}+\underset{(45 / 225)}{\mathrm{FSH}}+\mathrm{EGF} \\
(45)\end{array}$ & $97.77 \pm 0.94^{b}$ & $34.62 \pm 0.71^{c}$ & $80.44 \pm 1.85^{c}$ & $5.77 \pm 1.36^{b}$ \\
\hline $\mathbf{T}_{3}$ & $\begin{array}{l}\mathrm{T}_{4}+\mathrm{FSH}+\mathrm{GH} \\
+\mathrm{EGF}(45 / 225)\end{array}$ & $98.00 \pm 0.87^{b}$ & $42.66 \pm 2.06^{d}$ & $89.33 \pm 1.86^{d}$ & $15.55 \pm 2.09^{d}$ \\
\hline $\mathbf{T}_{4}$ & $\begin{array}{l}\mathrm{T}_{4}+\mathrm{FSH}+\mathrm{IGF} \\
+\mathrm{EGF}(45 / 225)\end{array}$ & $97.33 \pm 1.02^{b}$ & $41.00 \pm 1.33^{\mathrm{d}}$ & $82.22 \pm 1.58^{c}$ & $11.11 \pm 2.34^{c}$ \\
\hline $\mathbf{T}_{5}($ Control $)$ & $\begin{array}{l}\text { Control Media } \\
(45 / 225)\end{array}$ & $40.00 \pm 1.68^{\mathrm{a}}$ & $13.73 \pm 0.58^{\mathrm{a}}$ & $29.33 \pm 1.96^{\mathrm{a}}$ & $0.00^{\mathrm{a}}$ \\
\hline
\end{tabular}

Values with different superscripts within a column are significantly different $(\mathrm{P} \leq 0.05)$.

Table.2 Nuclear status and MII stage oocytes production of oocytes obtained from cultured PFs after $27 \mathrm{hrs}$ in vitro maturation in IVM media

\begin{tabular}{|c|c|c|c|c|c|c|}
\hline Treatments & $\begin{array}{c}\text { Combinations } \\
\text { (Replicates/ No. of } \\
\text { oocytes) }\end{array}$ & $\begin{array}{l}\text { GV } \\
(\%)\end{array}$ & $\begin{array}{c}\text { GVBD } \\
(\%)\end{array}$ & $\begin{array}{l}\text { M-II } \\
(\%)\end{array}$ & $\begin{array}{c}\text { Un } \\
\text { Classified } \\
(\%)\end{array}$ & $\begin{array}{l}\text { MII stage } \\
\text { oocytes } \\
\text { production }\end{array}$ \\
\hline$T_{1}$ & $\begin{array}{c}\mathrm{T} 4+\mathrm{FSH} \\
(6 / 48)\end{array}$ & $21.38 \pm 2.21^{\mathrm{a}}$ & $34.44 \pm 3.8^{b}$ & $19.07 \pm 2.17^{b}$ & $25.09 \pm 3.71^{\mathrm{c}}$ & $19.07 \pm 2.17^{b}$ \\
\hline $\mathbf{T}_{2}$ & $\begin{array}{c}\text { T4+FSH+EGF } \\
(6 / 41)\end{array}$ & $17.07 \pm 1.44^{\mathrm{a}}$ & $31.68 \pm 4.21^{\mathrm{b}}$ & $26.12 \pm 2.81^{b c}$ & $\begin{array}{l}20.88 \pm \\
4.56^{\mathrm{bc}}\end{array}$ & $26.12 \pm 2.81^{b}$ \\
\hline $\mathbf{T}_{3}$ & $\begin{array}{c}\mathrm{T} 4+\mathrm{FSH}+\mathrm{GH}+\mathrm{EGF} \\
(6 / 46)\end{array}$ & $26.97 \pm 2.24^{\mathrm{a}}$ & $26.03 \pm 2.77^{b}$ & $38.06 \pm 2.93^{d}$ & $10.73 \pm 2.33^{\mathrm{ab}}$ & $38.06 \pm 2.93^{\mathrm{d}}$ \\
\hline$T_{4}$ & $\begin{array}{c}\mathrm{T} 4+\mathrm{FSH}+\mathrm{IGF}+\mathrm{EGF} \\
(6 / 46)\end{array}$ & $24.24 \pm 2.96^{\mathrm{a}}$ & $34.81 \pm 3.84^{b}$ & $29.61 \pm 4.11^{\mathrm{c}}$ & $11.28 \pm 3.80^{\mathrm{ab}}$ & $29.61 \pm 4.11$ \\
\hline $\begin{array}{l}T_{5} \\
\text { (Control-I) }\end{array}$ & $\begin{array}{l}\text { Control-I } \\
(6 / 40)\end{array}$ & $55.64 \pm 2.81^{\mathrm{b}}$ & $0.00^{\mathrm{a}}$ & $0.00^{\mathrm{a}}$ & $44.35 \pm 2.81^{\mathrm{d}}$ & $0^{\mathrm{a}}$ \\
\hline $\begin{array}{l}\mathrm{T}_{6} \\
\text { (Control-II) }\end{array}$ & $\begin{array}{l}\text { Control-II } \\
(6 / 75)\end{array}$ & $17.17 \pm 1.97^{\mathrm{a}}$ & $32.62 \pm 3.19^{b}$ & $45.74 \pm 1.70^{\mathrm{e}}$ & $4.44 \pm 2.04^{\mathrm{a}}$ & $45.74 \pm 1.70^{\mathrm{e}}$ \\
\hline
\end{tabular}

Values with different superscripts within a column are significantly different $(\mathrm{P} \leq 0.05)$.

Statistically significant number of oocytes retrieved from PFs cultured in control media $\left(\mathrm{T}_{5}\right)$ were in $\mathrm{GV}$ stage $(55.64 \pm 2.81)$ compared to the treatments $\mathrm{T}_{1}, \mathrm{~T}_{2}, \mathrm{~T}_{3}, \mathrm{~T}_{4}$ and control-II $\left(\mathrm{T}_{6}\right)$. Highest $(\mathrm{P} \leq 0.05)$ numbers of oocytes from control-II (antral oocytes, T6) were matured to MII stage $(45.74 \pm 1.70)$. However, none of the oocyte retrieved from PFs cultured in control $\left(\mathrm{T}_{5}\right)$ were matured to MII stage. Among the treatments, oocytes 
retrieved from PFs cultured in $\mathrm{T}_{3}$ had exhibited the highest $(\mathrm{P} \leq 0.05)$ percentage of nuclear maturation to MII stage $(38.06 \pm 2.93)$ when compared to PFs of other treatments $T_{1}$, $\mathrm{T}_{2}$ and $\mathrm{T}_{4}$.

The present study demonstrated the effect of various growth factors and hormones like IGF, EGF, $\mathrm{T}_{4}, \mathrm{FSH}$ and $\mathrm{GH}$ in different combinations on in vitro development of goat preantral follicles. The present study advocated that the highest proportion of PFs exhibiting growth, increase in diameter, antrum formation and in vitro ovulation were in treatment groups cultured in combination of hormones and growth factors $\mathrm{T}_{4}+\mathrm{FSH}+\mathrm{GH}+\mathrm{EGF}\left(\mathrm{T}_{3}\right)$. These results are comparable with the findings observed by Zhou and Zhang (2005) who reported that, in presence of FSH, IGF-I in combination with EGF produced a higher survival rate of adult caprine preantral follicles than any other growth factor did individually. Findings of present study are in accordance with findings of Magalhaes et al., (2011b) in high rate of follicular survival and antrum formation when media supplemented with Growth hormone $(\mathrm{GH})$. Furthermore, the influence of the thyroxin on PFs appears to depend on the physiological status of the PFs at the time of collection (Gupta et al., 2007). Hence the present study proved that the in vitro development of goat PFs could be significantly improved through addition of $\mathrm{T}_{4}$, FSH, GH, EGF, and IGF-I in different combinations in the culture medium. Moreover, according to Gupta et al., (2007) age of the animal and season of the year at the time of isolation will also influence the in vitro development of preantral follicles.

However, immature oocytes in vivo remain arrested in the first meiotic prophase until maturation is induced by the interaction of steroids, gonadotropins and other follicular constituents. Full oocyte maturation involves not only acquisition of meiotic competency, but also cytoplasmic maturation. Use of different culture and maturation media in vitro with different supplements might improve the understanding of the minimal requirements for oocyte growth and maturation, expected to provide a reasonable yield of meiotically competent oocytes. Oocytes retrieved from PFs were grown in IVM culture media. In IVM media oocytes obtained from $\mathrm{T}_{3}$ treatment $\left(\mathrm{T}_{4}+\mathrm{FSH}+\mathrm{GH}+\mathrm{EGF}\right)$ had maximum percentage of M-II stage oocytes (38.6\%) in contrast to the findings of Arunakumari et al., (2010) in sheep, the difference might be due to variation in culture media or species difference. However, these findings were in accordance with the Magalhaes et al., (2011b) on production of matured oocytes by supplementation of Growth hormone at a concentration of $10 \mathrm{ng} / \mathrm{ml}$ and $50 \mathrm{ng} / \mathrm{ml}$. The present findings were in accordance with the results of Saraiva et al., (2012) who studied the effect of both FSH and LH on oocyte maturation. Meiotic resumption of oocytes from the present study was similar to the observations made by Saraiva et al., (2012) with the media supplemented with $\mathrm{LH}$ at concentration $50 \mathrm{ng} / \mathrm{ml}$. However, difference was noticed with LH supplemented at 100 $\mathrm{ng} / \mathrm{ml}$. It was reported by earlier studies that the effect of LH on the in vitro culture of preantral follicles depends on the follicular category, the concentration used and the timing of addition of LH to the culture medium (Tamilmani et al., 2005; Silva et al., 2011).

Most IVM protocols do employ luteinizing hormone (LH) or follicle stimulating hormone (FSH) or estradiol or a combination of them. Saraiva et al., (2012) reported that FSH increases the levels of $\mathrm{LH}$ receptor mRNA during in vitro culture of secondary follicles, ensuring a synergistic effect of both gonadotropins on follicular growth and 
meiotic resumption of oocytes recovered from goat preantral follicles cultured in vitro.

Chaves et al., (2012) reported that medium supplemented with $\mathrm{FSH}$ and Insulin at 10 $\mathrm{ng} / \mathrm{ml}$ presented oocytes, with higher rates of meiosis resumption as well as oocytes in metaphase II. The effect of both FSH and LH combination were studied earlier by Saraiva et al., (2012), the present findings were in accordance with the results of Saraiva et al., (2012).

From the present study, it can be concluded that, in vitro development of goat PFs could be significantly improved through addition of $\mathrm{GH}, \mathrm{EGF}, \mathrm{T}_{4}$ and $\mathrm{FSH}$ in best combinations.

\section{References}

Almeida, A. P., Saraiva, M. V. A., Araujo, V. R., Magalhaes, D. M., Duarte, A. B. G., Forta, I. M. A., Lopes. C. A. P., Campello, C. C., Silva, J. R. V. and Figueiredo, J. R. 2011. Expression of growth and differentiation factor 9 (GDF-9) and its effect on the in vitro culture of caprine preantral ovarian follicles. Small Ruminant Research. 100: 169-176.

Amin, R. U., Reddy, K. C., Rao, K. S., Raghavender, K. B. P., Teja, A., Ramesh, T., and Arunakumari, G. (2013). In vitro culture of goat preantral follicles from fetal ovaries. Small ruminant research. 115(1): 71-76.

Araujo, V. R., Chaves, R. N., Duarte, A. B. G., de Hollanda Celestino, J. J., da Silva G M, Fernandes, D. D., de Matos, M. H. T., Campello, C. C. and de Figueiredo, J. R. 2011. Effect of culture medium replacement protocol on the in vitro development of isolated caprine secondary follicles. Small Ruminant Research. 95: 139-143.
Arunakumari, G., Shanmugasundaram, N. and Rao, V. H. 2010. Development of morulae from the oocytes of cultured sheep preantral follicles. Theriogenology.74: 884-894.

Arunakumari, G., Vagdevi, R., Rao, B. S., Naik, B. R., Naidu, K. S., Suresh Kumar, R. V. and Rao, V. H. 2007. Effect of hormones and growth factors on in vitro development of sheep preantral follicles. Small Ruminant Research. 70: 93 - 100.

Eppig, J. J., O'Brien, M. J. 1996. Development in vitro of Mouse Oocytes from Primordial Follicles. Biology of Reproduction. 54: 197-207.

Gupta, P. S. P., Ramesh, H. S., Nandi, S. and Ravindra, J. P. 2007. Recovery of large preantral follicles from buffalo ovary: Effect of season and corpus luteum. Animal Reproduction Science. 101: 145-152.

Gupta, P. S. P., Ramesh. H. S., Manjunatha, B. M., Nandi, S. and Ravindra, J. P. 2008. Production of buffalo embryos using oocytes from in vitro grown preantral follicles. Zygote. 16: 57-63.

Liu, J., Van der Elst, J., Van den Broecke, R., and Dhont, M. 2001. Live offspring by in vitro fertilization of oocytes from cryopreserved primordial mouse follicles after sequential in vivo transplantation and in vitro maturation. Biology of Reproduction, 64(1): 171-178.

Magalhaes, D. M., Duarte, A. B. G., Araujo, V. R., Brito, I. R., Soares, T. G., Lima, I. M. T., Lopes, C. A. P., Campello, C. C., Rodrigues, A. P. R. and Figueiredo, J. R. 2011b. In vitro production of a caprine embryo from a preantral follicle cultured in media supplemented with growth hormone. Theriogenology. 75: 182-188.

Magalhaes, D. M., Fernandes, D. D., Mororo, M. B. S., Silva, C. M. G., Rodrigues, G. 
Q., Bruno, J. B., Matos, M. H. T., Campello, C. C. and Figueiredo, J. R. 2011a. Effect of the medium replacement interval on the viability, growth and in vitro maturation of isolated caprine and ovine pre-antral follicles. Reproduction in Domestic Animals. 46: 134-140.

Rao, B. S., Naidu, K. S., Amarnath, D., Vagdevi, R., Rao, A. S., Brahmaiah, K. V. and Rao, V. H. 2002. In vitro maturation of sheep oocytes in different media during breeding and nonbreeding seasons. Small Ruminant Research. 43(1): 31-36.

Saraiva, M. V. A., Brito, I. R., Chaves, R. N., Rodrigues, G. Q., Almeida, A. P., Lima, I. M. T., Rossetto, R., Frota, I. M. A., Leitão, C. C. F., Costa, J. J. N., Silva, J. R. V., Figueiredo, J. R. 2012. FSH and LH enhance the development of goat preantral follicles cultured in vitro. Animal Reproduction Science. 9(2): 7179.

Silva, C. M. G., Castro, S. V., Faustino, L. R., Rodrigues, G. Q., Brito, I. R., Saraiva, M. V. A., Rossetto, R., Silva, T. F. P., Campello, C. C. and Figueiredo, J. R.
2011. Moment of addition of LH to the culture medium improves in vitro survival and development of secondary goat pre-antral follicles. Reproduction in Domestic Animals. 46: 579-584.

Tamilmani, G., Rao, B. S., Vagdevi, R., Amarnath, D., Naik, B. R., Mutharao, M. and Rao, V. H. 2005. Nuclear maturation of oocytes in sheep preantral follicles cultured in vitro. Small Ruminant Research. 60: 295-305.

Wu, J., Carrell, D. T. and Wilcox, A. L. 2001b. Development of in vitro matured oocytes from porcine preantral follicles following intracytoplasmic sperm injection. Biology of Reproduction. 65: 1579-1585.

Wu, J., Emery, B. R. and Carrell, D. T. 2001a. In vitro growth, maturation, fertilization, and embryonic development of oocytes from porcine preantral follicles. Biology of Reproduction. 64: 375-381.

Zhou, H. and Zhang, Y. 2005. Effect of growth factors on in vitro development of caprine preantral follicle oocytes. Animal Reproduction Science. 90: 265272.

\section{How to cite this article:}

Shankaraiah, P., B. Swathi, G. Aruna Kumari, B. Priyanka, Ch. Srinivasa Prasad and Amin, R.U. 2018. Effect of Different Combinations of the Growth Factors and Hormones on In vitro Maturation of Goat Preantral Follicles. Int.J.Curr.Microbiol.App.Sci. 7(04): 1956-1963. doi: https://doi.org/10.20546/ijcmas.2018.704.224 